\title{
Developing a New Approach to Managing and Mediating Conflicts
}

\author{
Giulia Adriana Pennisi
}

DOI: http://dx.doi.org/10.7358/lcm-2017-001-penn

Online ISSN 2421-0293 - Print ISSN 2284-1881

\begin{abstract}
Generally speaking, words can be elusive and they need to be carefully selected when conveying messages, ideas and proposals between parties. This is all the more evident in mediation process as language has to be neutral and mediators should avoid expressions directing parties. In this regard, recent theoretical developments in postmodern social theory and the social constructionist movement in the social sciences and humanities have provided the field of alternative dispute resolution with a new approach to managing and mediating conflicts. These developments are organized around the 'narrative approach' which helps us to see how the language we use to describe and understand our conflicts are is operative in constructing an image in our minds of the conflict itself. The research conducted in this paper is in line with the theoretical principles behind the narrative mediation. By reframing the discourses surrounding the conflict situation, the analysis demonstrates that mediators might become aware of the peculiarities of mediation discourse and might be able to adapt the process to meet the particular circumstances in a knowledgeable way.
\end{abstract}

Keywords: ADR, communication, context, discourse, language, linguistic strategies, mediation, narrative approach, reframing.

\section{INTRODUCTION}

This article looks at the results of the analysis developed within the European project e-Medi@te - Workstream 3: Linguistic Competences in Mediation System (JUST/2011-2012/JCIV/AG/4000003440) ${ }^{1}$. The

1 The e-Medi@te project was funded by the European Commission within the Civil Justice 2012 Program and coordinated by the Department of European Studies and 
e-Medi@te project aims to create a training model for professionals and individuals who are interested in Alternative Dispute Resolution (ADR) across the European Union, in order to ease the use of mediation in the European countries and to reinforce European mediator skills on mediation techniques, e-Justice tools, and cross-cultural and linguistic communication. My role in the e-Medi@te project was to focus the attention on the language skills and linguistic strategies for practitioners who deal with mediation process, making them aware of the peculiarities of mediation discourse and able to adapt the process to meet the particular circumstances in a knowledgeable way.

To perform these roles, mediators need important communication strategies which are based on "effectiveness, impartiality and competency" as stated in Art. 3 of the Directive 2008/52/EC on certain aspects of mediation in civil and commercial matters:

Art. 3

(a) 'Mediation' means a structured process, however named or referred to, whereby two or more parties to a dispute attempt by themselves, on a voluntary basis, to reach an agreement on the settlement of their dispute with the assistance of a mediator. This process may be initiated by the parties or suggested or ordered by a court or prescribed by the law of a Member State. It includes mediation conducted by a judge who is not responsible for any judicial proceedings concerning the dispute in question. It excludes attempts made by the court or the judge seized to settle a dispute in the course of judicial proceedings concerning the dispute in question.

(b) 'Mediator' means any third person who is asked to conduct a mediation in an effective, impartial and competent way, regardless of the denomination or profession of that third person in the Member State concerned and of the way in which the third person has been appointed or requested to conduct the mediation. ${ }^{2}$

In the last few decades, ADR has become increasingly popular. Not only courts and government agencies in many countries have supported its use, but also mediation and conflict resolution organisations have been firmly established. Mediation, which is one of the ADR processes, has become the most significantly used non-adjudicatory one, with established pro-

International Integration (DEMS), University of Palermo (Italy), in collaboration with the Centre of Economic and Social Research for Southern Italy (Italy), the Mediterranean Centre for Intercultural Studies (Italy), the University of Piraeus (Greece), the University of Cyprus (Cyprus), the University of Tilburg (the Netherlands), the Galician Technological Institute (ITG). More information is available at http://www.emediate-justice.eu.

2 http://eur-lex.europa.eu/ [19/02/2017]. 
cedures and expectations. These transformations in the practice of public dispute management mostly coincided with a moment when legal scholarship and law practitioners became more interested in social sciences and take on a broader comparative view. Central to this growing concern was a return of attention to the negotiation and mediation processes. Interestingly enough, this development was signalled in the language used by some academic lawyers and legal practitioners when talking about conflict: the terms of conversation shifted from cases to dispute, from litigation to dispute processes, from judges to interveners (Roberts and Palmer 2005, 5). The common trend is to allow everyone to work as a mediator, but at the same time each model shapes the mediation market providing that the parties can realize certain goals and output (Damaška 1986; Markesinis 1990; Alexander 2006). In the jurisdictions belonging to civil law tradition, this development has largely taken place as a result of inspiration from the ADR movement in the Anglo-American law systems; whereas, the re-emergence of institutionalized mediation, the procedural reform of public justice system and the consequential adjustment within the legal professions have been all present in civil law countries ${ }^{3}$.

Saying that everyone can be a mediator (Hale 1998; Ware 2001; Kennedy 2009) is true, but we need quality standards which, in terms of regulatory models, involve that the traditional meaning of mediation (and mediation process) needs to be enlarged and improved by other elements.

\section{Corpus DESCRIPTION AND THEORETICAL PREMISES}

Many organizations offer accredited training to the general public in civil and commercial mediation. This following is a list of training organizations that I considered in my research. These organizations set out below have been recognised as meeting the required criteria to train mediators according to the standards provided by the EU, UK and US code of conduct for mediators.

- EU Code of Conduct for Mediators

A European Code of Conduct for Mediators sets out a number of principles to which individual mediators can voluntarily decide to commit,

3 For more information on this issue, see Pennisi 2014. 
under their own responsibility. It is intended to be applicable to all kinds of mediation in civil and commercial matters ${ }^{4}$.

- CMC (Civil Mediation Council) Accredited Mediation Providers 2013-2014 The CMC is the recognised authority in the country for all matters related to civil, commercial, workplace and other non-family mediation ${ }^{5}$.

- USA\&M

USA\&M is a client based ADR administrator providing a skilled panel of mediators and arbitrators to the legal, business and insurance community nationwide. It was established in 1985 and is now the largest provider of ADR in the Midwest ${ }^{6}$.

\section{- Library of Documents}

This site is intended to assist members access professional information and visitors to learn about mediation and the CMC. Library of Documents is available to all customers or anyone wishing to find out more information. Some of them also relate to family matters ${ }^{7}$.

- POCA \& Money Laundering

This site promotes an understanding of the value and practicalities of using mediation. It act as a link between all who are interested in mediation (the public, businesses, the professions and the government) and provide a forum for individuals, organisations and others to work collaboratively on mediation topics ${ }^{8}$.

- London School of Mediation

London School of Mediation offers mediation courses providing live experience as well as theory. It includes a professional demonstration of a recent case and new role plays from the case book for $2016^{9}$.

- The Academy of Experts

The Academy of Experts provides accreditation of Expert Witnesses and a comprehensive range of training courses to enable members and others to develop their expert skills. It was founded in 1987 with the objective of providing a professional body for experts to establish and promote high objective standards. The Academy of Experts provides accreditation of expert witnesses and a range of training courses to enable members and others to develop their expert skills ${ }^{10}$.

4 http://ec.europa.eu/civiljustice/adr/adr_ec_code_conduct_en.pdf [19/02/2017];

http://ec.europa.eu/civiljustice/adr/adr_ec_code_conduct_en.htm [19/02/2017].

5 http://www.civilmediation.org/ [19/02/2017].

6 http://usam.com [19/02/2017].

7 http://www.civilmediation.org/downloads.php?f=17 [19/02/2017].

8 http://www.civilmediation.org/downloads.php?f.=46 [19/02/2017].

9 http://www.schoolofmediation.org [19/02/2017].

10 http://www.academyofexperts.org/ [19/02/2017]. 


\section{- CEDR}

CEDR is the Centre for Effective Dispute Resolution and Mediation Advocacy Skill Training. This site provides case studies that represent a sample of its work in equipping individuals and teams with conflict management and resolution skills ${ }^{11}$.

\section{- Chartered Institute of Arbitrators}

The Chartered Institute of Arbitrators provides education and training for arbitrators, mediators and adjudicators. It also acts as a global hub for practitioners, policy makers and academics, supporting the development of all ADR methods. It offers a range of resources including guidance, support, advice, networking, as well as facilities for hearings, meetings and other events ${ }^{12}$.

\section{- MATA (Mediation and Training Alternatives)}

MATA is an online community for master mediators. MATA is a partnership based upon co-operative principles. All training is mediationcentred, the principles of which apply to negotiation, dispute avoidance as well as dispute resolution ${ }^{13}$.

The data, collected from the websites of the organizations listed above, have been divided into three sub-corpora, and consisted of transcribed texts of narrative mediation conversations ${ }^{14}$. Most of them do not represent the whole mediation process but rather different segments (about 2 billion words) of a role-played meeting between a mediator and the parties who decided to seek Family Mediation (FM, first sub-corpus), Employment Mediation (EM, second sub-corpus), and Conflict Resolution in Health Care (CRHC, third sub-corpus), before lawyers became involved. Starting from Labov's work on naturally occurring narratives (Labov and Waletzky 1967; Labov 1972; Bondi 2006), the analysis focused in particular on the role of story-telling in mediation from the indications provided by the recognized training organizations and code of conducts ${ }^{15}$.

\footnotetext{
11 http://www.cedr.com/skills/advocacy/?p=preparation [19/02/2017].

12 http://www.ciarb.org/ [19/02/2017].

13 https://mediationmastery.wordpress.com/ [19/02/2017]; https://mediationmastery.wordpress.com/tag/mediator-skills/ [19/02/2017].

14 The conversations have been taken from the websites of the organizations listed above.

15 As Bondi points out, the fully formed structure of narratives are: "a) Abstract: nutshell presentation of the story; b) Orientation: characters and setting in space and time; c) Complicating action: what happened then; d) Evaluation: reasons for the interest or importance of the story; e) Result or resolution: what happened finally; f) Coda: conclusion and return to present situation" (Bondi 2006, 56).
} 
The narrator and the audience assign praise and blame to the actors for the actions involved. The ways in which this is done are too varied to be reduced to a simple set of propositions. They include the use of linguistic devices of mood, factivity and causativity, evaluative lexicon, the insertion of and/or the omission of events (Billing 1988; Bhatia 1993 and 2004; Hansen 2004; Bhatia, Candlin, and Gotti 2010; White 2011). If we consider the ideological framework within which events are viewed (Fairclough 1989 and 1992; Labov 1997), then events can be seen as an essential part of the speaker's biography, as emotionally and socially evaluated, and so transformed from raw experience (Fowler et al. 1979; Fairclough 1995; Gergen and Thatchenkery 1996; Kahneman 2011). Furthermore, one might think that those who take the same moral stance will be more impressed by the narrative than those who do not, and therefore find it more credible as well as more interesting and engaging. For this reason, the narrator induces the audience to see the world through his/her own eyes (van Dijk 1985 and 1997), whereas discourses affect the extent to which a person's voice can be heard by another person (Chouliaraki and Fairclough 1999).

Within this descriptive theoretical framework, the present study looks at the possible alternative narratives that might been opened up or closed off by the position(s) established in the storylines that are privileged in each's person accounts (Huston and Thompson 2000; Winslade and Monk 2000 and 2008; Toolan 2001) as it will be shown in $\S 3$.

\section{Research Findings}

\subsection{Narrative signals}

The language focus of my analysis was on few selective features, including some features that Biber's (1988) multidimensional model lists along the narrative/non-narrative continuum (past tense verbs, third person pronouns, perfect aspect verbs, public verbs, syntactic negations and present participial clauses) ${ }^{16}$.

16 The analysis has been conducted in order to identify the systematic co-occurrence patterns among those linguistic features - the narrative dimension - and then texts have been compared along this dimension. The other features identified by the Biber Tagger (i.e., reduced forms and dispreferred structures, coordination, adjectives, adverbs and adverbials, adverbial subordination) have not been considered in the present research. 
These were studied in keywords and concordances. The quantitative analysis of the corpora provided this following result (Table 1) in terms of keywords produced by using Wordsmith Tools (Scott 2004).

Table 1. - General frequency data.

\begin{tabular}{cccccccc}
\hline N. & WORD & FM & $\%$ & EM & $\%$ & CRHC & $\%$ \\
\hline 3 & I & 9.320 & 0.37 & 5.771 & 0.22 & 6.354 & 0.18 \\
5 & you & 8.223 & 0.32 & 4.824 & 0.30 & 5.286 & 0.21 \\
8 & was & 8.829 & 0.33 & 3.654 & 0.13 & 9.806 & 0.35 \\
10 & were & 11.349 & 0.41 & 7.841 & 0.21 & 7.826 & 0.29 \\
11 & their & 1.087 & 0.04 & 8.822 & 0.31 & 2.143 & 0.09 \\
14 & relationship & 4.597 & 0.17 & 1.432 & 0.05 & 2.745 & 0.11 \\
18 & they & 1.153 & 0.05 & 4.341 & 0.18 & 3.927 & 0.15 \\
21 & thing(s) & 2.453 & 0.10 & 1.172 & 0.04 & 78 & \\
26 & nobody & 19 & & 1.773 & 0.04 & 124 & \\
27 & wrong & 189 & & 1.004 & 0.04 & 1.074 & 0.05 \\
28 & listen & 1.087 & 0.04 & 121 & & 1.203 & 0.05 \\
29 & care & 1.006 & 0.04 & 21 & & 2.805 & 0.11 \\
\hline
\end{tabular}

Table 1 illustrates selected results obtained when focusing on the words that are most frequent in three sub-corpora. Words included are the list of the non-specific lexical items in the top 30. The left-hand column indicates the position in the general list; the $3^{\text {rd }}$, the $5^{\text {th }}$, and the $7^{\text {th }}$ columns provide absolute and percentage frequencies in each of the three sub-corpora. Comparison of the wordlist in sub-corpora produced keywords, usually frequent or infrequent words in one sub-corpus when compared to the others. The fact that the other words in the list like family, children, parents are much more frequent in the FM with a total of 430 occurrences (against 11 in EM and 32 in CRHC), employee, contract, work life are much more frequent in the EM with a total of 123 occurrences (against 4 in FM and 20 in CRHC), and doctor, patient, and care are much more frequent in the CRHC with a total of 245 (against 23 in FM and 51 in EM) comes as no surprise.

What is interesting is the use of the word were, the third word in the list of the most frequent words in FM, EM, and CRHC. The difference in use of the simple past of the verb to be in the FM sub-corpus is likely 
to be interpreted in terms of the typical discursive procedure ${ }^{17}$ of family mediation because it is used to refer to a state of affairs in the past time (e.g. "They managed to arrive at an amicable solution, which meant Ann and Josephine were able to spend time with both mum and dad"; "We were all emotionally drained by my brother's divorce. There were long drawn out legal proceedings ... We're a close-knit family but my brother's divorce caused enormous divisions within the wider family", FM).

Then, words have been classified into two major classes. The first class includes narrative signals such as: past tense were and was, third person pro-forms like their and they, second person you. The rest of the words easily fall into references to the general process of mediation (relationship, wrong, things).

Concordance also provided material for closer study of patterns of semantic preference. If the presence of words like story, feedback, point, view, attention, listening, resolution refer to mediation methodology and tools, a closer analysis of the concordance would also show that in all the three sub-corpora emphasis is placed on typically narrative past tense ( $b a p$ pened, felt, asked, responded, did, suffered, perceived) and the presence of lexis typical of family domain (divorce 176 occurrences, bousework 69 occurrences, and education 41 occurrences in FM), employer and employee relationship (company 212 occurrences, and financial compensation 94 occurrences in EM), and heath care domain (treatment 223 occurrences, nurse 56 occurrences, and physician 31 occurrences). Similarly, the presence of technical terms like board members, shareholder, unjustified dismissal in EM, and hospitalized, medical personnel, chart, $X$ treatment in CRHC, confirm the preference for lexis inspired by labour law domain and medical domain respectively.

These results show that FM places more emphasis on typically narrative signals than the EM and CRHC sub-corpora. They also demonstrate that potentially narrative signals seem to be related to greater use of reflexive narrativity ${ }^{18}$ in FM corpora, and greater use of scenario reasoning in both EM and CRHC corpora.

17 For further reading on this topic see White and Morgan 2006.

18 In this perspective, narratives may be considered as a tool to access the interpretative framework that participants are using to construct their accounts of events and to make sense of their action. Therefore, narration includes not only the description of actions and events but also the participant's reasoning and motives (Sarbin 1986). Within stories participants insert a multiplicity of complex conceptual structures and transform transitory events and actions into stories that can be re-examined and revisited (Colombo 2003). 


\subsection{Tracing discursive positioning through conversation}

In order to gain a general overview it might be useful to divide the mediation process up into a number of stages, though it should be noted that mediation is a free and voluntary process and it might be conducted in a rather flexible way. Those stages may not be present in every case brought into the mediation and they may overlap in practice. In this respect, a general framework might consist of these following phases:

- pre-mediation: mediator informs parties about the mediation process and deals with queries;

- mediation process: mediator makes opening statement and asks parties to do the same; then, she/he identifies issues and sets an agenda, clarifying and exploring the issues previously identified; she/he negotiates and deals with impasse; eventually, she/he deals with a range of mediation outcomes;

- post-mediation: the mediator might have a post mediation function (i.e., stakeholder, continuing mediator, adjudicator, settlement supervisor).

The aim was to identify the narrative moves which characterize each of these stages in order to trace the discursive positioning of the participants in the mediation process. In this regard, the analysis has shown that it is possible to classify different types of narrative sections. The basic distinction can be found between (i) the narrative of engagement when the mediator sets the scene through opening statements (i.e., pre-mediation), followed by (ii) the narrative of 'deconstruction of conflict-saturated story' by means of neutrality and impartiality in the language used by mediator (i.e., mediation process), and (iii) the narrative of 'reframing' or constructing an alternative story (i.e., post-mediation).

\subsubsection{Narrative moves: engagement}

As the analysis indicates, one of the mediator's initial tasks is to establish the issues that the parties have agreed to resolve in mediation and establish an agenda for the process of mediation. In this stage, the mediator will carefully listen to each conflict story. These early communications introduce the mediator to the parties, give the mediator an initial picture of the issue under discussion, and set the process up effectively.

In this phase the mediator concentrates on establishing relationship with the conflicting parties. To achieve a workable relational context, the mediator needs to attend the physical setting in which the mediation is to take place and to direct the interactive moves made by the mediator and the parties. Discourse narrative can be typically exemplified by metadiscursive 
moves like the statement of an outline that refers to sequences of events as shown in example (1).

This extract is taken from FM sub-corpus and it is about a childcustody dispute ${ }^{19}$ which involved Susan, Mary and John. When Susan was nine, Eliza (Susan's mother) died from cancer. On hearing of Eliza's death, Susan's father, John, who had virtually no contact with his daughter since his separation from Eliza, decided that he should now have custody of Susan and stated his intentions to Mary (Susan's grandmother and Eliza's mother). Mary urged John to reconsider for everyone's sake. John was determined to file for custody of Susan but agreed with Mary that they would seek mediation before lawyers became involved.

(1) Mediator. "Thank you Mary and John for being here today ... I understand that the reason we're here is to discuss the primary caregiving arrangements for Susan ... and John I understand that you began the proceedings to look at caregiving arrangements ... What I would like to do to begin is to get a fuller understanding to the circumstances that have led to this meeting to discuss the care of Susan and so I'd like each of you take turns so we start with one of you, and the other, if you wouldn't mind, just being patient with me as we talk ... Who would like to begin?".

Mary. "This was his idea so I think that he should begin".

Mediator. "Well ... well, John? So, can you give me a little background as to what has led you to have the meeting? What is your thinking about that?". (FM; in all examples emphasis is added)

The mediator's focus here is on process issues, such as who will speak and in what order, a fair and even turn-taking norm for interaction, both parties having a say in the process, a request for patience while the other person is talking, and a norm of conversation control through addressing comments to the mediator rather than towards each other.

The content of the conversation is already being shaped by the choice of words used. The mediator recognizes the overall legal context in which the conversation participants are positioned as part of some proceedings, a word that carries traces of legal discursive practice. All three participants are aware of the implication of this type of discourse, through which the public power of the State can be exercised to shape the private world of the family. For this reason, the mediator carefully chooses words to describe the subject matter of this conversation as primary caregiving arrangements and the care of Susan. With this choice of words the mediator avoids direct-

19 The descriptive analysis has been informed by Winslade and Monk's seminal work on narrative mediation (2008). 
ing the discursive exchange toward the traditional legal discourse, as the choice of a word like 'custody' would do, and instead indicates a preference for the discourse of family relationship.

It is a stance that places the mediator in a position of perhaps mild antagonism to the hegemony of the dominant discourse. A neutral and impartial mediator should not take sides and decide who is right and who is wrong. The mediator should not give the parties the impression s/he is deciding what the most important issues are. To do that, the mediator should remind the parties' ownership of the outcome of mediation and keep asking for the parties' approval of the process in the course of engagement, making the opening statement (“... so I'd like each of you take turns so we start with one of you, and the other, if you wouldn't mind, just being patient with me as we talk ...").

\subsubsection{Narrative moves: deconstruction}

During deconstruction the mediator will challenge assumptions the parties make about each other, about themselves and about the conflict. The mediator should clarify that the persons are not the problem, the dispute is the problem, and they must jointly reconsider it. In order to do that, s/he should ask each party to outline what the dispute means to them not just in terms of identifying the issue(s), but also stating how they have been affected by them. Usually, the person who initiated the mediation is invited to begin. An example is provided in (2) where signals of the narrative of deconstruction are highlighted in italics. The conflict story that came to mediation with Belinda and Judith is about an employment relationship. It involved a merger of three companies in the financial services sector. As a result of the merger, they continued to work in the same office, but their roles had changed. Belinda was both a shareholder and an employee in the company, and she was working in the office four days per week. Belinda had been ill and believed that part of her distress could be due to her working relationship with Mark. Mark was a manager in a full-time position who has progressed rapidly in the company. In this case, restating, i.e. the subjective narration or description of the same problem or situation by each of the persons involved, may help clear up any misunderstandings and avoid problems early in the mediation.

(2) Mediator. "I'm going to ask each of you individually to present your point of view. The other person must listen to what is being said. To ensure this, I'm going to ask the other person to restate what was just said. So, for example: Belinda, you will complete presenting your point of view around 
a question I have asked; Mark, you will have to restate what Belinda just said. Is that process clear to both of you?".

Mediator. "How would you name the problem?".

BELINDA. "The last few weeks bave been a real roller coaster, Mark was kind on one minute and unpleasant the next".

MARK. "It was a personality clash. I don't agree with Belinda's view, but I understand that it was her perception". (EM)

This gives the mediator a brief sense of a simple, yet effective mediation opening. Gaining participation (extract [2]) through encouraging parties' active participation and respectful communication will go a long way toward achieving a successful outcome.

(3) MEdiator. "In addition, as we move along, I will also be asking each of you to present solutions to some of the problems brought up. As part of your solutions, I would like to hear what you believe are the possible consequences of your solutions being implemented. We will also follow the same restating process that I just brought up. All right, let's get started. Doctor Miller, I'll start with you". (CRHC)

To ensure parties' issues and concerns have been dealt with in an impartial and neutral way, mediator should take summary notes' of parties statements using a couple of direct quotations ("You made the point when you said that ..." / "The other thing you said was ..." / "You said that "the accident made me anxious" and avoiding expressions such as "The way I see your issues is ..." or "Now I understand that ..."). In particular, the pronoun you reinforces mediator's neutrality demonstrating that $\mathrm{s} / \mathrm{he}$ is simply quoting the party's statement/version and is not endorsing a particular version of the events.

This goal can be reached when the mediator is able to listen carefully to what parties are saying. In this regard, an often neglected communication skill is listening. Unless the circumstances require the mediator to interrupt a party for a specific reason, listening skills involve allowing the parties to speak without anticipating, contradicting or interrupting them, and understanding the situation so that mediator's appropriate interventions and responses occur to facilitate progressing the session, leading it to a possible resolution ("I will also be asking each of you to present solutions to some of the problems brought up"). It occurs when the mediator listens to what parties are saying and responds in active way reflecting the significance of what parties have stated ("What would happen if ...?", "How certain are you of ...?", "How certain do you think is the other party 
of ...?", "Why did you say that?") and their emotional content ("I notice that whenever we talk about ..., both of your voices rise, but I am not clear about why yet? Can you tell me?").

\subsubsection{Narrative moves: reframing}

Reframing or constructing an alternative story begins with the idea that a story of cooperation already exists and only needs to be uncovered. Words have to be used with extreme care when carrying messages, ideas and proposals between parties in the course of mediation (Moore 1996; Rotman 1997; Hale 1998). Whereas framing might refer to the way a conflict is described or a proposal is worded, "reframing is the process of changing the way a thought is presented so that it maintains its fundamental meaning but is more likely to support resolution efforts" (Mayer 2000, 132). Reframing occurs when the mediator changes either the words or the context of a party's statement by means of:

- restating what each party has said, using different words;

- putting a series of statements into a more logical sequence;

- restating an issue in more general terms;

- neutralising negative statements;

- mutualising parties' statements, emphasising commonality of interests.

Language needs to be neutral and mediators should avoid expressions directing parties ("I think you should ...", "It seems to me that you'd better doing ...”). Instead of distorting the meaning of a party's actions, mediators should allow those actions to be seen in a positive rather than negative way. Reframing is harder than it first appears, and none of the conceivable reframes are perfect. For these reasons, experts working in mediation provide some useful suggestions to improve the reframing technique ${ }^{20}$. More specifically, they suggest:

- To start with a neutral observation or a very general question. Then, they recommend to use the plural you/yours and welour whenever possible to build a sense of collaboration and emphasize a sense of commonality of interests.

(4) Mediator's Reframe: "It seems as if you are both focusing on important aspects of the work. So what if we have a discussion on past communication as your concerns seem linked to that?". (CRHC)

20 These examples are adaptations from those provided in Charlton and Dewdney 2004 and mediation websites http://www.mediate.com/index.cfm? classicsite=1 [19/02/2017]. 
- To neutralize and remove 'toxicity' while keeping the truth of the statement.

(5) Party's statement: "Ms. White is not reliable. She breached the contract".

MEDIATOR'S REFRAME: "Your concern is the way the contract was carried out". (EM)

- To redirect parties towards a positive future focus.

(6) Party's statement: "He has never been at home before 8:00 p.m. and I'm always back home at 6:30 p.m. I have to do everything alone".

MEDIATOR'S REFRAME: "So you are saying that for the future you would like to work on some plan that ensures you are both around at the same time, or which allows for a fair housework and dinner arrangement, for example, for you to alternate the late evening arrival". (FM)

- To soften demands.

(7) Party's statement: “Mrs. Harrows just won't admit that what she did was wrong and affected the whole team-work. I don't want to work with her anymore. History will only repeat itself".

MEDIATOR'S REFRAME: "You are saying how much this affected you and your team-work in the past and that things need to change in the future if you decide to work with her again”. (EM)

As the examples suggest, the mediator tones down on a blaming or critical statement and states it in a positive frame as in extract (6) "for the future you would like to work that ensures you are both around at the same time". Furthermore, the term future and the plural you, together with the volition verb form would like, help emphasizing common concerns or common ground.

For a better understanding of the reframing techniques listed above, we can take a look at the party's statement "You have to do something. No one in your family likes you!" and its possible alternative reframes (extracts [8], [9], [10], [11] and [12]):

(8) Mediator. "There appears to be some conflict between your family and you. How do you think the conflict could be resolved? What can you do to resolve the conflict? What do you need your family members to do to resolve the conflict?". (FM)

In this case mediator's reframe is too long and goes directly to a process for resolution with no exploration. The first sentence indicates that there is a possibility that the conflict might not exist. Another possible mediator's reframe might be 
(9) Mediator. "I've been hearing that there might be some conflict among family members. How do you think the conflict could be resolved? What can you do to resolve the conflict? What do you need your family members to do to resolve the conflict? Can we talk about that sometime?". (FM)

Here, the mediator has changed the first sentence in the reframe. The rest of the reframe has been retained, followed by an invitation to talk about that. Then, another possible mediator's reframe might be:

(10) Mediator. "Can you tell me how things are going with your family right now?”. (FM)

or:

(11) Mediator. "How're family members doing?". (FM)

In example (10), there is no implicit assumption. The mediator addresses the issue and $\mathrm{s} /$ he makes an appropriate question. The subjective pronoun you and the objective pronoun me are still there, but their importance/ power is reduced by comparison with examples (8) and (9).

In example (11), the question has been geared to maintain the focus of the concern and does not contain the subjective pronoun you and the objective pronoun me. Being an open-ended question the answer might be consistent with what the party wants to explore and might raise unexpected issues as well. At this point, another potential mediator's reframing might be this following with three slightly different versions.

(12) Mediator (option a): "I've been getting feedback that there may be some disagreement with your family right now. I want to be sure I have your feedback, so let's set aside a few minutes in the next day or two to talk about what might be happening".

MEDiator (option b): "It's come to my attention that there may be some disagreement with your family right now. I want to be sure I have your feedback, so let's set aside a few minutes in the next day or two to talk about what might be happening".

Mediator (option c): "Lately I've noticed that there may be some disagreement with your family right now. I want to be sure I have your feedback, so let's set aside a few minutes in the next day or two to talk about what might be happening". (FM)

In the previous examples ([8], [9], [10], [11]) the information is neutral, unbiased, with the use of the singular first person pronoun $I$. In example 12 option (a), the mediator makes a neutral observation using a first person 
pronoun $I$. Then the mediator gives a chance for exploration expressing the request for party's feedback ("I've been getting feedback that ..."). In particular, the modal auxiliary may suggests that the mediator assumes that the feedback hasn't been automatically accepted ("there may be"), whereas might indicates a discretionary act ("what might be happening"). The need expressed by the mediator to have the party's input indicates a collaborative approach, further emphasized by the exhortative "let's set aside". The use of the possessive form of the singular personal pronoun you ("your feedback") in the main clause of the mediator's second sentence, has the effect to produce a statement that does not feel like an accusation, but directly refers to the family members. As these examples show, the mediator enables the parties to own the issues and assures themselves that the problems raised throughout the mediation process will be properly explored.

\section{Concluding Remarks}

In this analysis we have pointed out that in mediation process language has to be neutral and mediators should redirect parties towards a positive future focus. To perform these roles, mediators need important communication strategies which are based on the "effectiveness, impartiality and competency" that Art. 3(b) of the Directive 2008/52/EC defines as the main rules of the mediation process. A mediator needs to be a proficient director and supervisor of the mediation process. This includes organizing the meetings, maintaining control over all procedural aspects, deciding how to conduct each element of the process, ensuring procedural fairness through a gentle, firm, effective and impartial management.

Recent theoretical developments in postmodern social theory and the social constructionist movement in the social sciences and humanities have provided the field of alternative dispute resolution with a new approach to dealing with and reconciling conflicts. These developments are organized around the 'narrative approach', which attempts to re-examine traditional theories of conflict mediation by investigating how the story/discourse we tell/narrate reflects conflicts, interests and positions. The analysis has shown that it is possible to classify three types of narrative moves: 'engagement' when the mediator sets the scene through opening statements ( $\S 3.2 .1)$; 'deconstruction of conflict-saturated story' by means of neutrality and impartiality in the language used by mediator ( $\$ 3.2 .2)$; and, 'reframing' or constructing an alternative story ( $\$ 3.2 .3)$. During engage- 
ment, the mediator will carefully listen to each conflict story. These early communications introduce the mediator to the parties (or their lawyers), give the mediator an initial picture of the issue under discussion, and set the process up effectively. As the analysis indicates, one of the mediator's initial tasks is to establish the issues that the parties have agreed to resolve in mediation and establish an agenda for the process of mediation. During deconstruction the mediator will challenge assumptions the parties make about each other, about themselves and about the conflict. Then, reframing and construction begin with the idea that a story of cooperation already exists and only needs to be disclosed. Although relatively limited as far as the materials are concerned, the analysis conducted in this paper provides elements evidencing that language awareness and linguistic knowledge among legal practitioners represents an important step towards the creation of a more efficient alternative dispute resolution area. The present contribution might be considered a first step in that direction.

\section{REFERENCES}

Alexander, Nadja M. 2006. Global Trends in Mediation. London: Kluwer Law International.

Bhatia, Vijay K. 1993. Analysing Genre: Language Use in Professional Settings. London New York: Longman.

Bhatia, Vijay K. 2004. Worlds of Written Discourse. London: Continuum.

Bhatia, Vijay K., Christopher N. Candlin, and Maurizio Gotti, eds. 2010. The Discourses of Dispute Resolution. Bern: Peter Lang.

Biber, Douglas. 1988. Variation Across Speech and Writing. Cambridge: Cambridge University Press.

Billing, Michael. 1988. Ideological Dilemmas: A Social Psychology of Everyday Thinking. London: Sage.

Bondi, Marina. 2006. “'A Case in Point': Signals of Narrative Development in Business Economics". In Academic Discourse Across Disciplines, edited by Ken Hyland and Marina Bondi, 49-74. Bern: Peter Lang.

Charlton, Ruth, and Micheline Dewdney. 2004. The Mediator's Handbook. Sydney: Law Book Co. of Australasia.

Chouliaraki, Lilie, and Norman Fairclough. 1999. Discourse in Late Modernity: Retbinking Critical Discourse Analysis. Edinburg: Edinburgh University Press.

Colombo, Monica. 2003. "Reflexivity and Narratives in Action Research: A Discursive Approach". Forum Qualitative Sozialforschung / Forum Qualitative Social Research 4 (2), Art. 9. [19/02/2017]. http://nbn-resolving.de/ urn:nbn:de:0114-fqs030291. 
Damaška, Mirjan R. 1986. The Faces of Justice and State Authority. New Haven London: Yale University Press.

Fairclough, Norman. 1989. Language and Power. Longman: Harlow.

Fairclough, Norman. 1992. Discourse and Social Change. Cambridge: Polity Press.

Fairclough, Norman. 1995. Critical Discourse Analysis: The Critical Study of Language. London: Longman.

Fowler, Roger, Bob Hodge, Gunther Kress, and Tony Trew. 1979. Language and Control. London: Routledge and Kegan Paul.

Gergen, Kenneth J., and Tojo Joseph Thatchenkery. 1996. "Organization Science as Social Construction: Postmodern Potentials”. Applied Behavioral Science 32: 356-377. [19/02/2017]. http://journals.sagepub.com/doi/pdf/ $10.1177 / 0021886396324002$.

Hale, Katherine. 1998. “The Language of Cooperation: Negotiation Frames”. Mediation Quarterly 16 (2): 147-162.

Hansen, Toran. 2004. “The Narrative Approach to Mediation”. Pepperdine Dispute Resolution Law Journal 4 (2): 1-12. [18/02/2017]. https://www.researchgate. net/publication/254667214_The_Narrative_Approach_to_Mediation.

Huston, Susan, and Geoff Thompson. 2000. Evaluation in Texts: Authorial Stance and the Construction of Discourse. Oxford: Oxford University Press.

Kahneman, Daniel. 2011. Thinking, Fast and Slow. New York: Farrar, Straus and Giroux.

Kennedy, Gavin. 2009. Negotiation. London: The Economist.

Labov, William. 1972. Language in the Inner City. Philadelphia: Philadelphia University Press.

Labov, William. 1997. "Some Further Steps in Narrative Analysis". The Journal of Narrative and Life History 7: 395-415. doi: 10.1075/jnlh.7.49som.

Labov, William, and Joshua Waletzky. 1967. "Narrative Analysis: Oral Versions of Personal Experience". In Essays on the Verbal and Visual Arts, edited by June Helm, 12-44. Seattle: University of Washington Press.

Markesinis, Basil S. 1990. "Litigation-mania in England, Germany and the USA: Are We So Very Different?”. Cambridge Law Journal 49 (02): 233-276. doi: 10.1017/S0008197300117039.

Mayer, Bernard. 2000. The Dynamics of Conflict Resolution. San Francisco: Jossey-Bass. Moore, Christopher. 1996. The Mediation Process. San Francisco: Jossey-Bass.

Pennisi, Giulia A. 2014. "Mediation Process: Increasing Language Awareness and Developing Communication Skills". In Mediation in Europe: At the Cross-road of Different Legal Cultures, edited by Antonello Miranda, 261-287. Roma: Aracne.

Roberts, Simon, and Michael Palmer. 2005. Dispute Processes: ADR and the Primary Forms of Decision-making. Cambridge: Cambridge University Press.

Rotman, Jay. 1997. Resolving Identity-based Conflicts in Nations, Organizations and Communities. San Francisco: Jossey-Bass. 
Sarbin, Theodore R. 1986. Narrative Psychology: The Storied Nature of Human Conduct. New York: Praeger.

Scott, Mike. 2004. Wordsmith Tools. Oxford: Oxford University Press.

Toolan, Michael. 2001. Narrative: A Critical Linguistic Introduction. London - New York: Routledge.

van Dijk, Teun A. 1985. Handbook of Discourse Analysis. London: Academic Press.

van Dijk, Teun A. 1997. Discourse Studies: A Multidisciplinary Introduction. London: Sage.

Ware, Stephen J. 2001. Alternative Dispute Resolution. St. Paul (MN): West Group.

White, Michael. 2011. Narrative Practice: Continuing the Conversations. New York: W.W. Norton \& Company.

White, Michael, and Alice Morgan. 2006. Narrative Therapy with Children and Their Families. Adelaide (South Australia): Dulwich Centre Publications.

Winslade, John, and Gerald Monk. 2000. Narrative Mediation: A New Approach to Conflict Resolution. San Francisco: Jossey-Bass.

Winslade, John, and Gerald Monk. 2008. Practicing Narrative Mediation: Loosening the Grip of Conflict. San Francisco: John Wiley \& Sons. 